\title{
Analisa Pengaruh Penerapan Bulbous Bow Terhadap Pemakaian Bahan Bakar pada Kapal Trawler Vessel di Perairan Laut Arafura
}

\author{
Perlambang Kasih Djatmiko, Tony Bambang, Amiadji \\ Jurusan Teknik Sistem Perkapalan, Fakultas Teknologi Kelautan, Institut Teknologi Sepuluh Nopember (ITS) \\ Jl. Arief Rahman Hakim, Surabaya 60111 Indonesia \\ email: tobal@its.ac.id,amiadji@its.ac.id
}

\begin{abstract}
Abstrak - Laut Arafura memiliki potensi produksi lestari lebih kurang 770.000 ton ikan per tahun. Kini di perairan itu beroperasi 776 kapal berbendera Indonesia dan 592 kapal berbendera asing dengan total produksi lebih dari 990.000 ton ikan . Namun kondisi ombak di Laut Arafura yang terkadang kurang bersahabat mengakibatkan kapal penangkap ikan sulit melakukan manuver di perairan Laut Arafura. Saat ini telah dilakukan berbagai penelitian dalam bidang desain kapal yang bertujuan untuk meningkatkan hasil yang optimum. Salah satunya adalah dalam hal tahanan dan konsumsi pemakaian bahan bakar. Dalam penelitian ini peneliti ingin mengetahui pengaruh modifikasi terhadap lambung kapal dengan menambahkan bulbous bow untuk meningkatkan manuver terhadap mempengaruhi tahanan kapal serta konsumsi bahan bakar kapal. Dalam proses pengerjaan peneliti menguji model kapal non bulbous bow serta kapal yang menggunakan bulbousbow model $O$, Segitiga dan $V$ menggunakan softwarenumeca. Hasil pengerjaan skripsi ini di dapatkan perbandingan tahanan kapal dan jumlah konsumsi bahan bakarnya.
\end{abstract}

Kata kunci- Laut Arafura, Trawler Vessel, Tahanan kapal, konsumsi bahan bakar, Bulbous bow

\section{PENDAHULUAN}

L aut Arafura memiliki potensi produksi lestari lebih kurang 770.000 ton ikan per tahun. Kini di perairan itu beroperasi 776 kapal berbendera Indonesia dan 592 kapal berbendera asing dengan total produksi lebih dari 990.000 ton ikan [1]. Namun kondisi ombak di Laut Arafura yang terkadang kurang bersahabat mengakibatkan kapal penangkap ikan sulit melakukan manuver di perairan Laut Arafura. Saat ini telah dilakukan berbagai penelitian dalam bidang desain kapal yang bertujuan untuk meningkatkan hasil yang optimum. Salah satunya adalah dalam hal tahanan dan konsumsi pemakaian bahan bakar.

Dalam perencanaan desain kapal, tahanan akibat gelombang adalah salah satu komponen penting pada tahanan kapal. Pada umumny,a rasio kerampingan lambung kapal yang besar dibutuhkan untuk mengurangi tahanan akibat gelombang.

Jenis Kapal yang umumnya sering dijumpai adalah kapal yang mempunyai lambung tunggal atau monohull. Pada kapal monohull, untuk mencapai kecepatan yang tinggi dengan efisiensi bahan bakar yang baik maka lambung kapal dibuat seramping mungkin untuk mengurangi tahanan gelombang.
Namun, kekurangan dari ini adalah mengurangi stabilitas kapal. Oleh karena itu, diperlukan penambahan bulbous bow sebagai pengurang tahanan pada kapal sekaligus pemecah ombak agar kapal dapat bermanuver lebih baik serta berfungsi sebagai stabilitas kapal. Namun hal ini jelas akan mempengaruhi penggunaan bahan bakar pada kapal ikan.

\section{DASAR TEORI}

\section{A. Laut Arafura}

Secara umum, Laut Arafura mempunyai tipe pasang surut tunggal, dimana dalam satu hari terjadi pola satu kondisi air pasang dan satu kali surut, sementara ketika mendekati pesisir barat daya Papua maka tipe pasang surut berevolusi menjadi bertipe campuran (Pranowo \& Wirasantosa, 2011). Pada umumnya kecepatan angin di wilayah laut ini berkisar antara 10-25 knot dan bergerak dari timur laut hingga tenggara [3].

\section{B. Trawler Vessel}

Pada abad ke 17 perahu dogger dibuat oleh bangsa Inggris yang merupakan kapal pukat dan rawai pertama dan beroperasi di laut utara. Nama dogger diambil dari bahasa Belanda, dogger yang berarti "kapal pukat". Istilah dogger bank digunakan oleh bangsa Belanda untuk menyebut kawasan tempat menangkap ikan dengan pukat. Dogger merupakan kapal yang lambat, namun tangguh dan mampu menangkap ikan di Laut Utara yang memiliki cuaca yang ekstrim. Kapal ini lebar dengan panjang 15 meter, lebar 4.5 meter, draft 1.5 meter, dan displacement 13 ton. Kapal ini mampu mengangkut satu ton umpan, tiga ton garam, setengah ton makanan dan kayu bakar, serta kembali dengan enam ton ikan hasil tangkapan

\section{Tahanan Kapal}

Tahanan Kapal merupakan gaya hambat dari media fluida yang dilalui oleh kapal saat beroperasi dengan kecepatan tertentu. Besarnya gaya hambat total merupakan jumlah dari semua gaya hambat yang bekerja dikapal, gaya hambat total tersebut meliputi tahanan gesek, tahanan tekanan, tahanan gelombang, tahanan tambahan digelombang, tahanan udara. 


\section{Bulbous bow}

Bulbous adalah suatu bentuk konstruksi haluan yang berbentuk bulat telur yang ditempatkan pada linggi haluan bagian depan. Perbandingan model percobaan menunjukkan bahwa sebuah kapal yang dilengkapi dengan Bulbous Bow dapat membutuhkan sedikit daya pendorong dan memiliki ketahanan yang jauh lebih baik karakteristik dari kapal yang sama tanpa menggunakan Bulbous Bow.

Bulbous adalah suatu bentuk konstruksi haluan yang berbentuk bulat telur yang ditempatkan pada linggi haluan bagian depan. Perbandingan model percobaan menunjukkan bahwa sebuah kapal yang dilengkapi dengan Bulbous Bow dapat membutuhkan sedikit daya pendorong dan memiliki ketahanan yang jauh lebih baik karakteristik dari kapal yang sama tanpa menggunakan Bulbous Bow.

Bulbous Bows pertama kali diperkenalkan pada tahun 1912 oleh angkatan laut Amerika Serikat, yang diperkenalkan oleh David Taylor. Namun hingga tahun 1950 tidak memperlihatkan perkembangan yang berarti. Bahkan pada batas waktu tersebut tidak pernah dijumpai pemakaiannya pada kapal-kapal barang.

\section{Bentuk-bentuk Bulbous Bow}

Pemilihan bentuk untuk suatu kapal tergantung dari beberapa faktor, antara lain:

- Kondisi perairan

- Lebar kapal, panjang kapal, kelangsingan kapal.

Ir. Mansyur Hasbullah, M. Eng membagi bentuk Bulbous Bows yang berpengaruh terhadap Terhadap Horse Power yaitu:

1. Bentuk titik air terbalik; Bentuk ini sangat cocok untuk kapal-kapal yang bergelombang.Bentuk ini sering dikombinasikan pada kapal-kapal yang bergading "V" yang digunakan pada kapal-kapal berkecapatan tinggi . Bentuk ini sangat cocok untuk kapal-kapal yang bergelombang. Dan digunakan pada kapal-kapal berkecapatan tinggi .

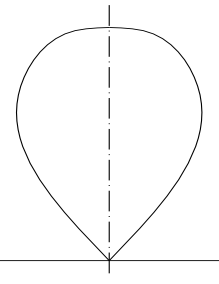

Gambar 1. Bulbous Bow bentuk titik air terbalik Sumber: Universitas Makasar, Harnita

2. Bentuk titik air bergantung; Bentuk ini, sesuai dengan kapal-kapal yang berlayar pada daerah yang kurang menghadapi hempasan gelombang yang besar. Namun bentuk ini sangat lemah terhadap benturan
Gambar 2. Bulbous bow bentuk titik air bergantung

3. Bentuk Elips; Bentuk Bulbous yang ketiga ini lebih banyak digunakan pada kapal-kapal yang bentuk gadingnya "U" atau kapal-kapal yang berukuran gemuk namun bentuk ini tahan terhadap benturan ombak



Gambar 3. Bulbous bow bentuk elips

\section{E. Main Engine}

Mesin kapal yang berfungsi sebagai tenaga penggerak kapal, nantinya mesin ini bertugas untuk menggerakan propeller / baling - baling kapal yang selanjutnya mendorong air dan menggerakan kapal dengan satu propeller hanya mempunyai satu mesin induk sedangkan kapal yang mempunyai dua propeller atau twin screw digerakan oleh dua mesin induk

\section{F. Sistem Bahan Bakar Kapal}

Sistem bahan bakar adalah suatu sistem pelayanan untuk motor induk yang sangat vital. Sistem bahan bakar secara umum terdiri dari fuel oil supply, fuel oil purifiering, fuel oil transfer dan fuel oil drain piping system. System bahan bakar adalah suatu system yang digunakan untuk mensuplai bahan bakar dari bunker ke service tank dan juga daily tank dan kemudian ke mesin induk atau mesin Bantu. Adapun jenis bahan bakar yang digunakan diatas kapal bisa berupa heavy fuel oil (HFO), MDO, ataupun solar biasa tergantung jenis mesin dan ukuran mesin. Untuk system yang menggunakan bahan bakar HFO untuk opersionalnya, sebelum masuk ke main engine (Mesin utama) HFO harus ditreatment dahulu untuk penyesuaian viskositas, temperature dan tekanan.

Untuk system bahan bakar suatu mesin, semua komponen yang mendukung sirkulasi bahan bakar harus terjamin kontinuitasnya karAena hal tersebut sangat vital dalam operasional, maka dalam perancangan ini setiap komponen utama system harus ada yang standby (cadangan) dengan tujuan jika salah satu mengalami trouble/disfungsi dapat secara otomatis terantisipasi dan teratasi. Peralatan tersebut antara lain 
: purifier pump, supply pump, circulating pump, filter, dan lain-lain [11].

\section{METODOLOGI}

Dalam penelitian ini menggunakan metode berbasis ComputationalFluidDynamic(CFD). Penggambaran model menggunakan model serta simulasi dari model didukung dengan software dengan basis yang Numeca.Setelah di temukan tahanan kapal dari software tersebut, ditemukan nilai kebutuhan untuk memilih power mesin. Setelah itu di temukanlah perhitungan bahan bakar.

\section{HASIL PERCOBAAN}

Proses awal dari penelitian ini adalah dengan membuat model kapal dengan variasi bulbous bow sehingga di dapatkanlah hasil berikut ini

Model bulbous bow dimana dari perhitungan didapatkan:



Gambar 4. Bulbous bow segitiga

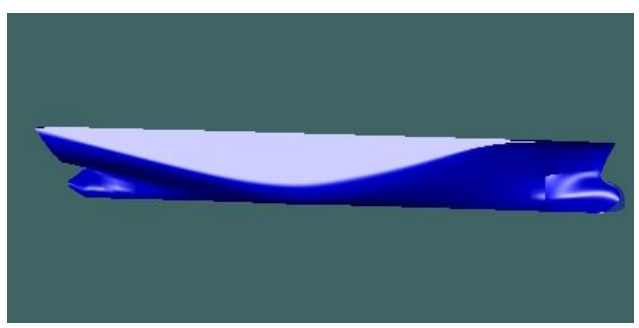

Gambar 5. Kapal dengan variasi bulbous bow segitiga

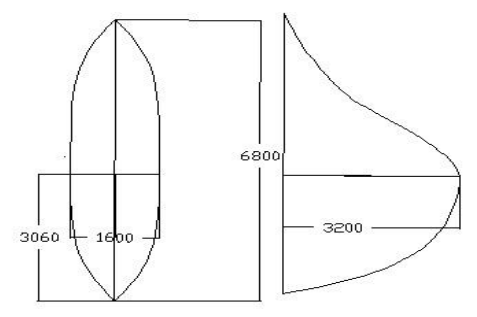

Gambar 6. Bulbous bow O

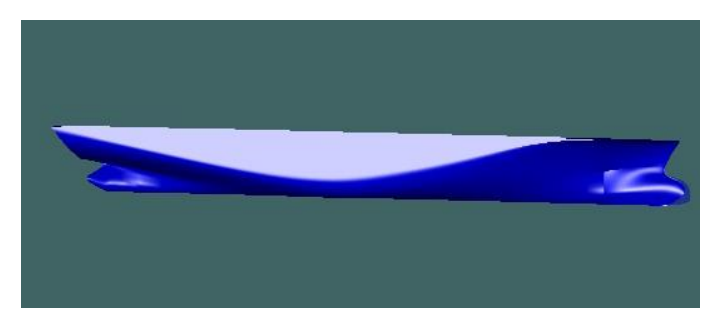

Gambar 7. Kapal dengan variasi bulbous bow $\mathrm{O}$

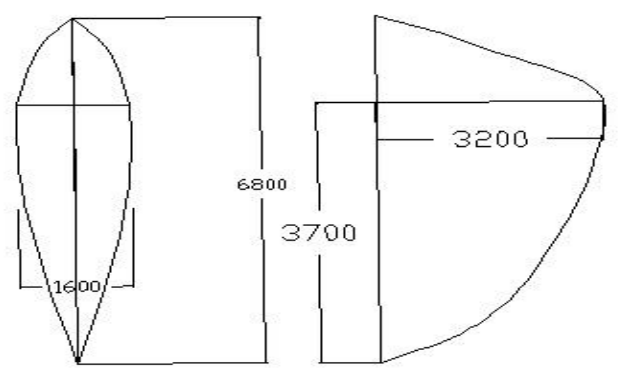

Gambar 8. bulbous bow V

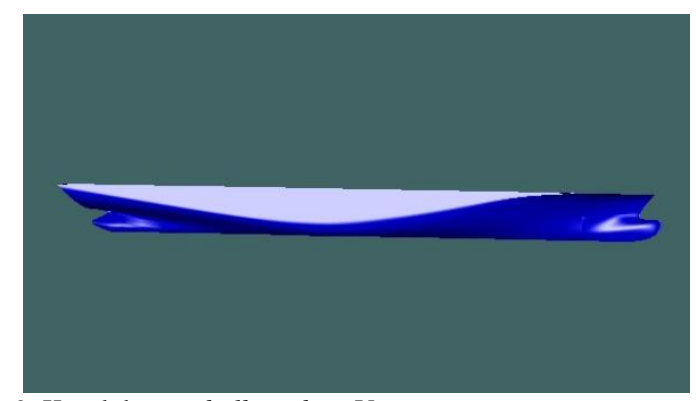

Gambar 9. Kapal dengan bulbous bow V

Kemudian model tersebut dimasukan ke solidwork untuk di solidkan sebelum di uji pada Numeca Fine Marine. Setelah itu di laksanakan pengujian untuk mengetahui hasil tahanan kapal
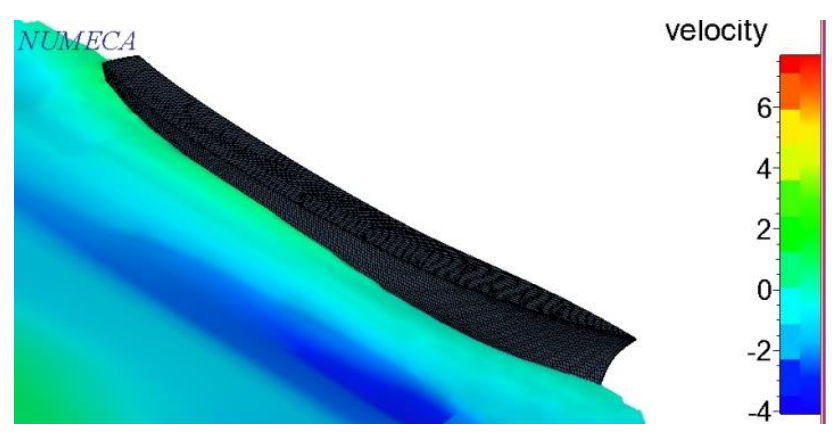

Gambar 10. Gambar aliran air hasil simulasi

Dari hasil pengujian tersebut diketahui bahwa kapal yang memiliki bulbousbow memiliki tahanan lebih kecil dari yang tanpa menggunakannya, dimana model $\mathrm{V}$ memiliki tahanan kapal yang paling kecil, hal ini sesuai dengan teori bahwa salah satu fungsi utama bulbousbow adalah untuk mengurangi 
tahanan pada kapal [5]. Pada kapal tanpa bulbous bow koefisien hambatan total semakin bertambah besar. Hal tersebut terjadi karena pengaruh dari hambatan gelombang yang timbul saat kapal bergerak baik akibat pola gelombang yang ditimbulkan kapal maupun aliran gelombang atau air di sekitar badan kapal dimana saat kapal bergerak semakin cepat dan mendekati nilai tertentu maka hambatan akan bertambah dengan cepat.

Pada kapal dengan bulbous bow koefisien hambatan total cenderung bertambah kecil. Hal tersebut terjadi karena pengaruh dari bentuk bulbous bow pada bagian haluan kapal sehingga hambatan kapal dapat berkurang.

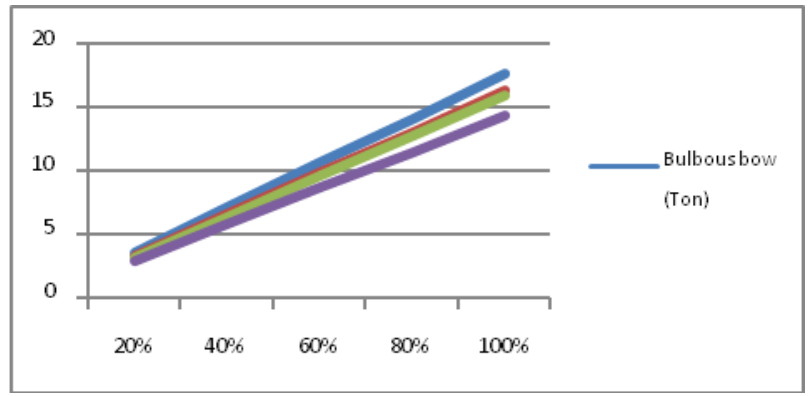

Gambar 11. Grafik perbandingan konsumsi bahan bakar kapal

Dari hasil diatas didapatkan bahwa bubousbow tipe V yang memiliki tahanan paling kecil membutuhkan kebutuhan bahan bakar yang paling sedikit, hal ini menunjukan bahwa semakin kecil tahanan kapal akan semakin kecil juga pemakaian bahan bakar, hal ini dikarenakan tahanan kapal menjadi acuan untuk menghiung jumlah daya yang di gunakan dalam pemilihan main engine. Dimana dalam main engine yang kita pilih tersebut memiliki project guide yang mencantumkan spesifikasi mesin yang digunakan dalam menghitung kebutuhan bahan bakar, yaitu jumlah konsumsi bahan bakar (g/kwh) serta daya power mesin (kw) yang berbeda pada tiap main engine.

\section{KESIMPULAN}

Berdasarkan hasil penelitian diatas di ketahui bahwa penggunaan bulbousbow dapat mengurangi tahanan kapal yang dapat mempengaruhi dalam menentukan kebutuhan power dalam pemilihan mesin utama kapal, dimana semakin kecil power yang di butuhkan maka akan semakin kecil juga nilai dari kebutuhan bahan bakar. Selain itu hal lain yang mempengaruhi jumlah kebutuhan bahan bakar adalah konsumsi bahan bakar yang berbeda tiap mesinnya. Dalam hal ini kapal bulbousbow model V memiliki tahanan serta kebutuhan bahan bakar yang lebih kecil.

\section{DAFTAR PUSTAKA}

[1] G. W. Juette and L. E. Zeffanella, "Radio noise currents n short sections on bundle conductors (Presented Conference Paper style)," presented at the IEEE Summer power Meeting, Dallas, TX, Jun. 22-27 (1990) Paper 90 SM 690-0 PWRS.

[2] J. G. Kreifeldt, "An analysis of surface-detected EMG as an amplitude-modulated noise," presented at the 1989 Int. Conf. Medicine and Biological Engineering, Chicago, IL.

[3] J. Williams, "Narrow-band analyzer (Thesis or Dissertation style)," Ph.D. dissertation, Dept. Elect. Eng., Harvard Univ., Cambridge, MA (1993).

[4] N. Kawasaki, "Parametric study of thermal and chemical nonequilibrium nozzle flow,” M.S. thesis, Dept. Electron. Eng., Osaka Univ., Osaka, Japan (1993).

[5] J. P. Wilkinson, "Nonlinear resonant circuit devices (Patent style)," U.S. Patent 3624 12, July 16, (1990).

[6] IEEE Criteria for Class IE Electric Systems (Standards style), IEEE Standard 308 (1969).

[7] Letter Symbols for Quantities, ANSI Standard Y10.5 (1968).

[8] R. E. Haskell and C. T. Case, "Transient signal propagation in lossless isotropic plasmas (Report style)," USAF Cambridge Res. Lab., Cambridge, MA Rep. ARCRL-66-234 (II) (1994), Vol. 2.

[9] E. E. Reber, R. L. Michell, and C. J. Carter, "Oxygen absorption in the Earth's atmosphere," Aerospace Corp., Los Angeles, CA, Tech. Rep. TR-0200 (420-46)-3 (Nov. 1988).

[10] (Handbook style) Transmission Systems for Communications, 3rd ed., Western Electric Co., Winston-Salem, NC (1985) 44-60.

[11] Motorola Semiconductor Data Manual, Motorola Semiconductor Products Inc., Phoenix, AZ (1989). 